\title{
The Selective Neuronal NO Synthase Inhibitor 7-Nitro-Indazole Blocks Both Long-Term Potentiation and Depotentiation of Field EPSPs in Rat Hippocampal CA1 In Vivo
}

\author{
Ciaran Doyle, ${ }^{1}$ Christian Hölscher, ${ }^{2}$ Michael J. Rowan, ${ }^{2}$ and Roger Anwyl ${ }^{1}$ \\ Departments of ${ }^{1}$ Physiology and ${ }^{2}$ Pharmacology and Therapeutics, Trinity College, Dublin 2, Ireland
}

The membrane-permeant gas $\mathrm{NO}$ is a putative intercellular messenger that has been proposed on the basis of previous in vitro studies to be involved in synaptic plasticity, especially the induction of long-term potentiation (LTP) of excitatory synaptic transmission in the hippocampus and cortex. In the present study, the role of NO in synaptic plasticity has been investigated in vivo. In particular, the action of the novel and selective neuronal NO synthase (nNOS) inhibitor 7-nitro-indazole (7-NI) has been investigated on the induction of LTP and depotentiation (DP) of field EPSPs in CA1 of the hippocampus in vivo. Unlike previously studied nonselective NOS inhibitors, 7-NI does not increase arterial blood pressure. In vehicle-injected rats, high-frequency stimulation consisting of a serles of trains at $200 \mathrm{~Hz}$ induced LTP. However, LTP induction was strongly inhibited in $7-\mathrm{NI}(30 \mathrm{mg} / \mathrm{kg}$, i.p.)-treated animals. The inhibitory effect of $7-\mathrm{NI}$ on the induction of LTP was prevented by pre- treatment with L-arginine, the substrate amino acid used by NOS. In control animals, low-frequency stimulation consisting of 900 stimuli at $10 \mathrm{~Hz}$ induced DP of previously established LTP, whereas in 7-NI-treated animals only a short-term depression was induced. This effect of 7-NI also was prevented by $D$-arginine. The LTP and DP induced in control animals in this study were NMDA receptor-dependent, the NMDA receptor antagonist 3-(R,S)-2-carboxypiperazin-4-yl-propyl-1phosphonic acid inhibiting the induction of both forms of synaptic plasticity. The present experiments are the first to demonstrate that an NOS inhibitor blocks the induction of the synaptic component of LTP and DP in vivo and, therefore, these results strengthen evidence that the production of NO is necessary for the induction of LTP and DP.

Key words: NO; 7-nitro-indazole; neuronal NO synthase; longterm potentiation; depotentiation; CA1 region; hippocampus
Long-term potentiation (LTP) is a long-lasting enhancement of synaptic transmission induced by high-frequency afferent stimulation that is the basis of certain cellular models of memory (Bliss and Lomo, 1973; for review, see Bliss and Collingridge, 1993). Conversely, depotentiation (DP) is the eradication of previously established LTP and usually is induced by low-frequency afferent stimulation (Barrionuevo et al., 1980; for review, see Linden, 1994). The induction of LTP is known to be postsynaptic in origin via, at least in part, the activation of NMDA receptors (Collingridge et al., 1983), whereas the expression of LTP may be partially mediated presynaptically via an increasc in transmitter release (Dolphin et al., 1982; Bliss and Collingridge, 1993). Therefore, it has been hypothesized that a retrograde messenger links the postsynaptic and presynaptic cells. The diffusible molecule NO has been proposed as one such retrograde messenger.

NO was shown to be formed in the cerebellum after activation of NMDA receptors (Garthwaite et al., 1988) and was proposed to be an intercellular messenger (Garthwaite et al., 1988; Bredt and Snyder, 1989; Gally et al., 1990). NO is produced from the enzymatic conversion of L-arginine to L-citrulline by NO synthase (NOS). Experimental evidence consistent with the theory that NO acts as a retrograde messenger in LTP has been presented based on several lines of evidence in the $\mathrm{CA} 1$ region of rat hippocampus in vitro. First, the NOS inhibitors $\mathrm{L}-\mathrm{N}^{\mathrm{G}}$-monomethylarginine (L-

\footnotetext{
Received June 22, 1995; revised Sept. 8, 1995; accepted Sept. 27, 1995.

This work was supported by grants from the Health Research Board of Ireland, the European Commission, and the Wellcome Trust.

Correspondence should be addressed to Dr. Anwyl, Physiology Department, Trinity College, Duhlin 2, Ireland.

Copyright (C) 1995 Society for Neuroscience $0270-6474 / 95 / 160418-07 \$ 05.00 / 0$
}

NMMA), L-N ${ }^{G}$-nitroarginine (L-NOARG), and its methyl ester derivative (L-NAME) blocked the induction of LTP of the EPSP (Bohme et al., 1991; O’Dell et al., 1991; Schuman and Madison, 1991; Bon et al., 1992; Haley et al., 1992), an effect partially reversed by a precursor of NO, L-arginine (Haley et al., 1992). Second, agents that bind NO, such as hemoglobin, also blocked the induction of LTP (O'Dell et al., 1991; Schuman and Madison, 1991; Bon et al., 1992; Haley et al., 1992). Third, NO donors such as sodium nitroprusside and hydroxylamine produced a longlasting enhancement of excitatory synaptic transmission that was not additive with LTP (Bohme et al., 1991). Fourth, direct application of NO converted the short-term potentiation (STP) produced by weak, high-frequency stimulation into an LTP (Zhuo et al., 1993). L-NMMA also inhibited LTP in the frontal cortex in vitro (Nowicky and Bindman, 1993).

However, many later in vitro studies have raised doubts about $\mathrm{NO}$ acting in a simple way as a retrograde messenger. First, the ability of NOS inhibitors to block LTP is highly variable. For example, very large differences in potencies of NOS inhibitors in their ability to block LTP were found in one study, despite a relative similarity in the ability to inhibit NOS; L-NMMA, in particular, was only marginally active in blocking LTP (Bon et al., 1992). L-NOARG also was shown to be ineffective in blocking LTP, despite inhibition of NOS (Cummings et al., 1994). Second, the protocols of stimulation used to induce LIP were found to be critical in producing a block of LTP by NOS inhibitors, although no uniformity was found in different studies. Thus, NOS inhibitors were found to block LTP induced by weak, but not intense, high-frequency stimulation in three studies (Chetkovitch et al., 1993; Haley et al., 1993; O'Dell et al., 1994). However, another 
study demonstrated that NOS inhibitors were effective in reducing LTP induced by intense, but not weak, high-frequency stimulation (Gribkoff and Lum-Ragan, 1992; Lum-Ragan and Gribkoff, 1993). NOS inhibitors were found in one in vitro study to produce an effective block only at room temperature in young animals weighing between 70 and $100 \mathrm{gm}$ (Williams et al., 1993). However, a blocking effect of NOS inhibitors at high temperatures $\left(>30^{\circ} \mathrm{C}\right)$ (Bohme et al., 1991; Bon et al., 1992; Gribkoff and Lum-Ragan, 1992; Haley et al., 1993; Lum-Ragan et al., 1993; Nowicky and Bindman, 1993) and in older animals weighing between 100 and 200 gm (Bohme et al., 1991; Bon et al., 1992; I Ialey et al., 1993) has been observed. Studies on the effects of NO donors also have raised doubts about the role of NO in long-term synaptic plasticity. Thus, Boulton et al. (1994) found that several NO donors induced a transient synaptic depression, but not LTP or LTD, in CA1 in vitro.

To date, in vivo studies have not clarified the role of NO in the induction of LTP, because although the blocking action of intracerebroventricular L-NAME on LTP of the population spike in the dentate gyrus (Iga et al., 1993; Mitzuni et al., 1993) was confirmed in one study (Bannerman et al., 1994a), neither inhibition of the induction of LTP of the EPSP nor population spike was found when the drug was given systemically in a later study by the same group (Bannerman et al., 1994b). Because there are differences in the sensitivity of different hippocampal pathways to NOS inhibitors even within the same subregion (Nicolarakis et al., 1994), it is important to determine whether NO has a role in synaptic plasticity in CA1 in vivo. The NOS inhibitors used previously, such as L-NAME, significantly increased peripheral blood pressure, decreasing cerebral blood flow to brain regions including the hippocampus (Lot et al., 1993; Bannerman et al., 1994b). Some of the older NOS inhibitors have other side effects that complicate the interpretation of their in vivo effects; for example, L-NAME antagonizes muscarinic acetylcholine receptors (Buxton et al., 1993). In the present studies, therefore, we have studied the effects of a novel NOS inhibitor, 7-nitro-indazole (7-NI), on the induction of both LTP and DP in CA1 in vivo. This compound is selective for neuronal NOS (nNOS) in vivo (Babbedge et al., 1993; Moore et al., 1993a) and has no effect on mean arterial blood pressure at doses that produce a marked reduction in NOS activity, i.e., $20-80 \mathrm{mg} / \mathrm{kg}$, i.p. (Moore et al., 1993a,b).

\section{MATERIALS AND METHODS}

This study was performed using male Wistar rats weighing 250-350 gm (BioResources Unit, Trinity College, Dublin, Ireland). The rats were anesthetized with urethane (ethyl carbamate, $1.5 \mathrm{gm} / \mathrm{kg}$, i.p.) for the duration of all experiments. All animals were maintained on a halothane/ oxygen ( $1 \%$ halothane in pure oxygen; flow rate, $1 \mathrm{l} / \mathrm{sec}$ ) gas mixture during the implantation procedure only. Recovery from halothane was assessed by measuring electroencephalogram activity, which usually took less than $30 \mathrm{~min}$.

Recordings of field EPSPs were made from the CA1 stratum radiatum of the right hippocampal hemisphere in response to stimulation of the Schaffer collateral-commissural pathway. Burr holes $1.5 \mathrm{~mm}$ in diameter were drilled over the unilateral electrode implantation sites, which were identified using stereotaxic coordinates relative to bregma and lambda, with the recording site located $3 \mathrm{~mm}$ posterior and $2 \mathrm{~mm}$ lateral to the midline and the stimulating electrode $4 \mathrm{~mm}$ posterior to bregma and 3 $\mathrm{mm}$ lateral to the midline. Bipolar stimulating and monopolar recording electrodes consisted of two pieces of twisted tungsten wire attached to a connecting socket insulated along its length with a Teflon coat except at the tips. The dura mater was pierced, and the electrodes were lowered slowly through the cortex and the upper layers of the hippocampus into the CA1 region until the appearance of a negative deflecting EPSP. The electrodes then were fixed in place with cyanoacrylate glue and acrylic dental cement for the stimulation and recording of evoked field EPSPs.
Stainless steel screws fixed to the skull served as ground (anterior, $7 \mathrm{~mm}$; lateral, $5 \mathrm{~mm}$ ) and reference (posterior, $8 \mathrm{~mm}$; lateral, $1 \mathrm{~mm}$ ) electrodes.

In all experiments, control EPSPs were evoked at a frequency of 0.033 $\mathrm{Hz}$ and an input-output curve (stimulus intensity vs EPSP amplitude) was plotted for each experiment at this test frequency. For the control EPSPs, the stimulation voltage intensity was adjusted to give an EPSP amplitude of $50 \%$ of maximum input-output amplitude. LTP was induced using either one set or three sets of trains of stimuli, each set of trains being 10 trains of 20 stimuli (interstimulus interval, $5 \mathrm{msec}$ ( 200 $\mathrm{Hz}$ ); intertrain interval, $2 \mathrm{sec}$; interset interval, $5 \mathrm{~min}$ ). The three sets were used in the experiments investigating the effects of 7-NI on LTP, whereas the single set was used in the DP and 3-(R,S)-2-carboxypiperazin-4-yl-propyl-1-phosphonic acid (CPP) studies. The low-frequency stimulation used to induce DP consisted of 900 stimuli at $10 \mathrm{~Hz}$ which, in previous studies in this laboratory, was found to evoke maximal DP. The stimulation intensity was increased to give an EPSP of $75 \%$ maximum amplitude during the stimulation used to induce LTP.

All recording and stimulation was performed using an on-line computerized oscilloscope/stimulator and data analysis interface system (MacLab/2e). Unless otherwise stated, all data are expressed as mean \pm SEM percent baseline EPSP amplitude. Statistical tests were carried out using nonparametric Wilcoxon and parametric $t$ tests, and the significance level in all cases was $p<0.05$.

All drugs used in this study were applied intraperitoneally at the times indicated in the text. 7-NI (Affiniti Research Products) was administered as an emulsified suspension in the fat-soluble vehicle sesame oil (Tesco), prepared in a sonicator immediately before use. 7-NI $(9 \mathrm{mg})$ was prepared in $2 \mathrm{ml}$ of sesame oil to give a final concentration of $30 \mathrm{mg} / \mathrm{ml}$ and was administered intraperitoneally to the animal after a 10 min control recording period. Previous studies have shown that $30 \mathrm{mg} / \mathrm{kg}$, i.p. inhibited NOS in the hippocampus by 85 and $45 \%$ at $30 \mathrm{~min}$ and $4 \mathrm{hr}$ respectively, after injection (Mackenzie et al., 1994). L-Arginine was obtained from Sigma Ltd. (Poole, UK). CPP was obtained from Tocris Cookson Ltd.

\section{RESULTS \\ The effect of urethane and 7-NI on baseline EPSP amplitude}

EPSPs were elicited at the control test frequency of $0.033 \mathrm{~Hz}$ for $2 \mathrm{hr}$ to determine the effect of the anesthetic urethane $(1.5 \mathrm{gm} / \mathrm{kg})$ on the test EPSP amplitude. Figure $1 a$ (top) shows that the amplitude of the EPSPs did not change signiticantly over the 90-100 min recording period. For example, the EPSP amplitude at 10,60 , and 100 min from the start of the recording period measured $101 \pm 2,103 \pm 2$, and $99 \pm 5 \%$, respectively $(n=4, p>$ 0.05). Similarly, 7-NI $(30 \mathrm{mg} / \mathrm{kg})$ had no significant effect on the test EPSP amplitude over an $80 \mathrm{~min}$ period, the EPSP measuring $100 \pm 4 \%$ for the $5 \mathrm{~min}$ preceding drug administration, $102 \pm 5 \%$ at $25-30 \mathrm{~min}, 96 \pm 8 \%$ at $55-60 \mathrm{~min}$, and $103 \pm 10 \%$ at $75-80$ min after injection ( $n=3, p>0.05$; Fig. $1 a$, bottom).

\section{The effect of 7-NI on the induction of LTP}

7-NI was found to inhibit significantly L.TP induced by strong, high-frequency stimulation consisting of three sets of highfrequency trains. In these experiments, recordings first were made from two control groups of rats. In one set of control rats injected with the vehicle sesame oil, the amplitude of LTP 20 min after stimulation measured $156 \pm 14 \%(n=6$; Fig. $1 b)$. This value was not significantly different from noninjected control rats (155 \pm $11 \%, n=5$; data not shown). It can be seen from Figure $1 b$ that the second and third sets, but not the first set, of high-frequency trains induced a short-term depression lasting up to $5 \mathrm{~min}$ in the control rats. In the experimental group of rats, 7-NI was administered after a $10 \mathrm{~min}$ control recording period, and test EPSPs were monitored for $30 \mathrm{~min}$ to determine whether there was an effect of the drug on the baseline amplitude. There was no significant difference between the EPSP amplitude measured 30 min after 7-NI was applied and the EPSP amplitude measured 
a
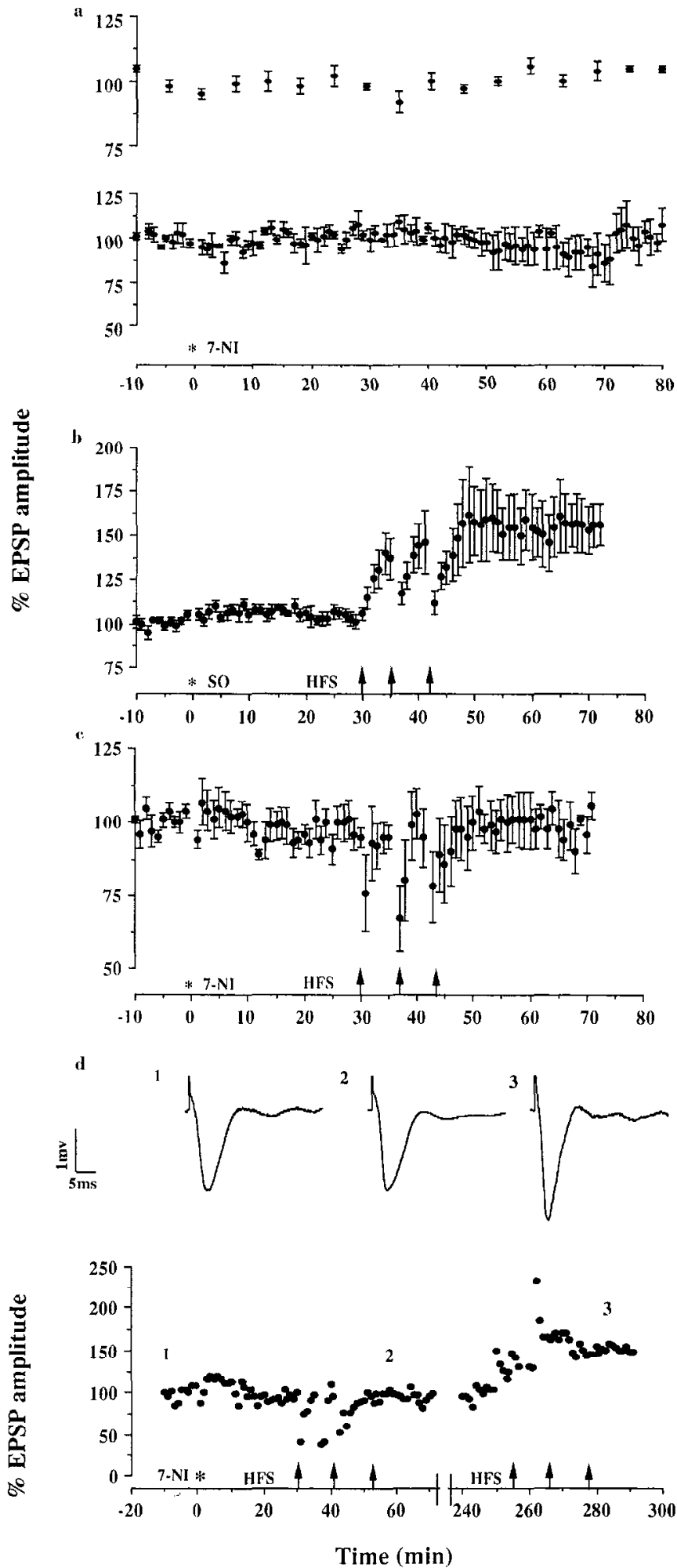

Figure 1. The effect of 7-NI and its vehicle on the field EPSP amplitude and LTP in the CA1 of the hippocampus. $a$, Top: urethane $(1.5 \mathrm{~g} / \mathrm{kg}$, i.p.) does not affect the baseline EPSP significantly over the duration of the experiments, the EPSP measuring $101 \pm 2,103 \pm 2$, and $99 \pm 5 \%$ at 10 , 60 , and $100 \mathrm{~min}$, respectively, from the start of recording $(n=4)$. Bottom: $7-\mathrm{NI}(30 \mathrm{mg} / \mathrm{kg}$, i.p.) does not affect the baseline EPSP over the duration of the experiment, the EPSP measuring $100 \pm 4 \%$ over the $5 \mathrm{~min}$ preceding 7-NI injection and $102 \pm 5,96 \pm 8$, and $103 \pm 10 \%(n=3)$ at $25-30,55-60$, and $75-80 \mathrm{~min}$, respectively, after injection. $b$, Sesame oil did not affect EPSP amplitude or the induction of LTP by three highfrequency trains [high-frequency stimulation $(H F S)$ indicated by arrows], during the preinjection control period $(n=6, p>0.05)$. In this experimental group, 7-NI completely blocked the induction of LTP, the value of the EPSP amplitude at $20 \mathrm{~min}$ after stimulus measuring $97 \pm 13 \%(n=6)$. This was a significant reduction in LTP ( $p<0.05$; Fig. $1 c$ ) compared with the vehicle control group. It can be seen from Figure $1 c$ that all three sets of high-frequency trains of stimuli induced a short-term depression lasting up to 5 min in animals injected with 7-NI.

In three experiments, high-frequency stimulation was applied at $30 \mathrm{~min}$ and $4 \mathrm{hr}$ after the injection of 7-NI. 7-NI inhibited the induction of LTP when the high-frequency stimulation was given at $30 \mathrm{~min}$ after injection (mean, 101\%). However, robust LTP averaging $158 \%$ was elicited by the high-frequency stimulation when applied at $4 \mathrm{hr}$ after 7-NI injection (Fig. $1 d$ ).

\section{The effect of L-arginine on the action of $7-\mathrm{NI}$ on LTP induction}

I.-Arginine, the substrate amino acid used by NOS for NO production, was found to reverse partially the inhibitory effect of 7-NI on the induction of LTP. In these experiments, L-arginine (225 $\mathrm{mg} / \mathrm{kg}$ ) was given intraperitoneally $60 \mathrm{sec}$ before application of the drug or the vehicle. In the control group of rats, the effect of L-arginine was investigated on baseline responses and on the induction of LTP. There was no significant effect of the amino acid on the test EPSP amplitude $(100 \pm 2 \%$ before administration of L-arginine vs $100 \pm 3 \% 30$ min later; $n=6, p>0.05$ ). High-frequency stimulation induced LTP measuring $140 \pm 7 \%$ ( $n=4$, Fig. $2 a$ ). In the experimental group of rats, high-frequency stimulation in the presence of L-arginine and 7-NI $(30 \mathrm{mg} / \mathrm{kg}$ ) induced LTP of $134 \pm 6 \%(n=5, p>0.05$ compared with L-arginine alone; Fig. $2 b$ ). This was a significantly greater amplitude of the EPSP than that observed in the group of rats injected only with 7-NI $(97 \pm 13 \% ; n=6, p<0.05)$.

\section{The effect of 7-NI on the induction of DP}

7-NI was found to inhibit the induction of DP. In a control group of rats, high-frequency stimulation resulted in stable LTP measuring $163 \pm 16 \%$ at $25-30 \mathrm{~min}$ after the tetanus and $160 \pm 16 \%$ at 55-60 min after the tetanus $(n=5, p>0.05)$. In a separate group of rats, DP of $77 \%$ was induced by applying low-frequency stimulation, consisting of 900 stimuli at $10 \mathrm{~Hz}, 30 \mathrm{~min}$ after inducing LTP. Thus, the EPSP measured $135 \pm 5 \%$ at $25-30 \mathrm{~min}$ after the tetanus and $108 \pm 3 \%$ at $25-30 \mathrm{~min}$ after low-frequency stimulation ( $n=5, p<0.05$ compared with the potentiated level; Fig. $3 a)$. In the experimental group of rats, $7-N I(30 \mathrm{mg} / \mathrm{kg})$ was administered $60 \mathrm{scc}$ after high-frequency stimulation, and the EPSP amplitude was monitored as before for $30 \mathrm{~min}$. LTP at this time measured $152 \pm 12 \%(n=6)$. Low-frequency stimulation ( 900 pulses at $10 \mathrm{~Hz}$ ) induced a short-term depression lasting $10-15 \mathrm{~min}$ with a maximum decrease to $111 \pm 20 \%$ at $60 \mathrm{sec}$ after stimulus, but induced no DP, the EPSP amplitude fully recovering by $25-30 \mathrm{~min}$ after low-frequency stimulation to a value not

\footnotetext{
the amplitude of LTP at 20 min after stimulation measuring $156 \pm 14 \%(n$ $=6) . c, 7-\mathrm{NI}$ inhibited the production of LTP by three high-frequency trains, with LTP at 20 min after high-frequency stimulation measuring 97 $\pm 13 \%(n=6, p<0.05)$. $d$, Recovery of LTP in a single experiment $4 \mathrm{hr}$ after the administration of 7-NI. Three high-frequency trains failed to induce significant LTP in this experiment after injection of 7-NI, whereas $3.5 \mathrm{hr}$ later robust LTP was induced. Insets show representative traces at the points indicated on the graph. An asterisk indicates when the drug or vehicle was administered. All data points are mean \pm SEM.
} 


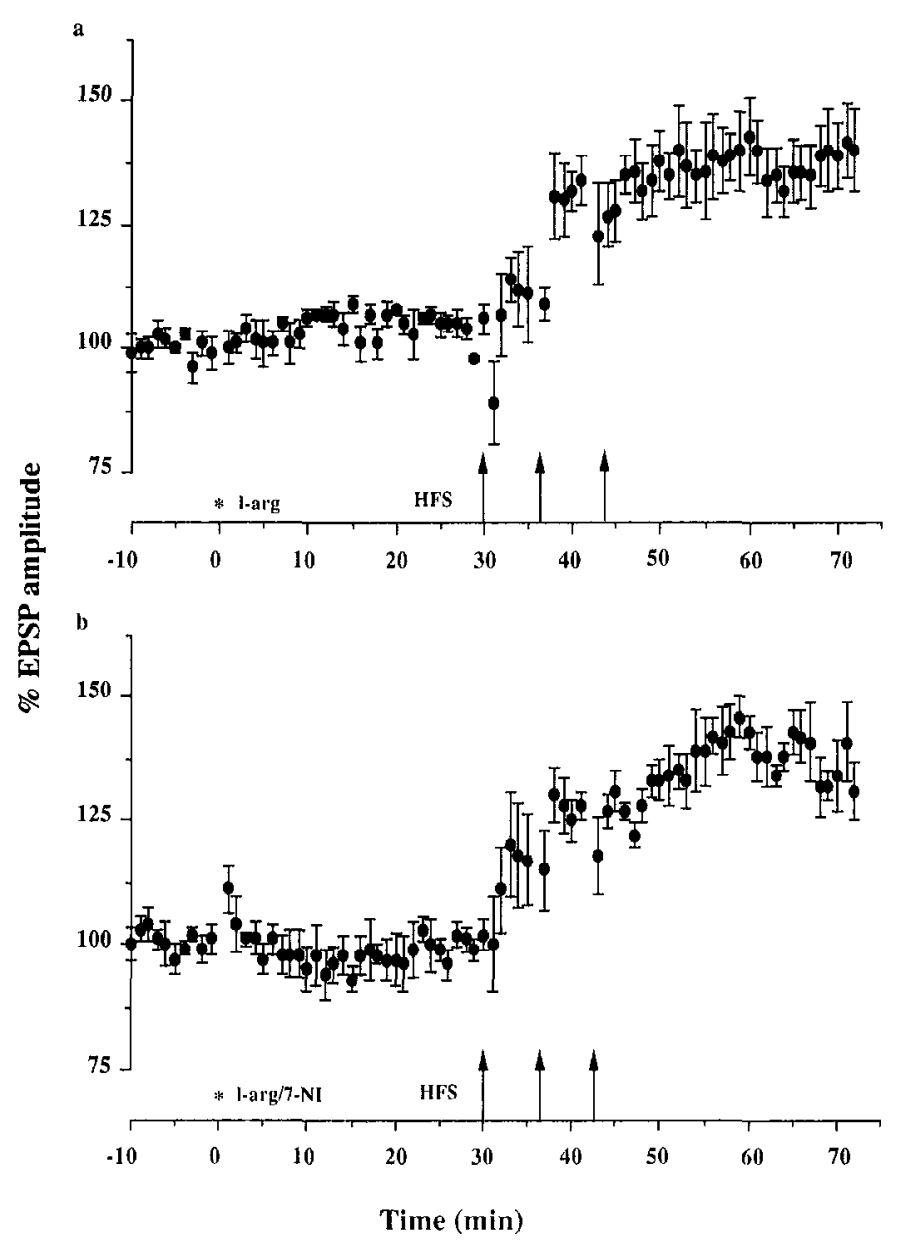

Figure 2. L-Arginine prevented the effect of 7-NI on LTP. $a$, L-Arginine $(225 \mathrm{mg} / \mathrm{kg}$, i.p.) had no significant effect on the test EPSP amplitude or on the induction of LTP (LTP $140+7 \%, n=4) . b$. L-Arginine $(225 \mathrm{mg} / \mathrm{kg}$ i.p.) administered $60 \mathrm{sec}$ before 7-NI $(30 \mathrm{mg} / \mathrm{kg}$, i.p.) partially overcame the inhibition of induction of LTP by 7-NI (LTP $134 \pm 6 \% 25-30$ min after tetanus, $n=5$ ). All drug administrations are indicated by asterisks; sets of high-frequency stimulations are indicated by arrows.

significantly different from the previous potentiated level $(154 \pm$ $11 \%$; Fig. $3 b$ ).

\section{The effect of L-arginine on the action of 7-NI on the induction of DP}

L-Arginine was found to prevent fully the inhibitory effect of 7-NI on the induction of DP. LTP was induced by high-frequency stimulation in a group of rats $(147 \pm 13 \%, n=7)$, with $\mathrm{L}$-arginine injected 2-3 min later followed by a $7-\mathrm{NI}(30 \mathrm{mg} / \mathrm{kg})$ injection. After another $30 \mathrm{~min}$, low-frequency stimulation induced DP, the amplitude of the EPSP measuring $113 \pm 6 \% 25-30 \mathrm{~min}$ after low-frequency stimulation. This is a reduction of $72 \%$ in the potentiated EPSP amplitude, a value that was significantly different from that of rats injected with 7-NI alone in which no DP occurred $(p<0.05$; Fig. $3 c)$.

\section{The effect of CPP on LTP and DP}

Because previous studies have shown that NMDA receptor activation leads to stimulation of NO production, the action of the NMDA receptor antagonist CPP was investigated on the induction of LTP and DP. CPP ( $7 \mathrm{mg} / \mathrm{kg})$ inhibited the induction of LTP (Fig. 4a). Thus, the EPSP amplitude $20 \mathrm{~min}$ after tetanus was $106 \pm 4 \%$ in rats that had been injected with CPP at $30 \mathrm{~min}$ before
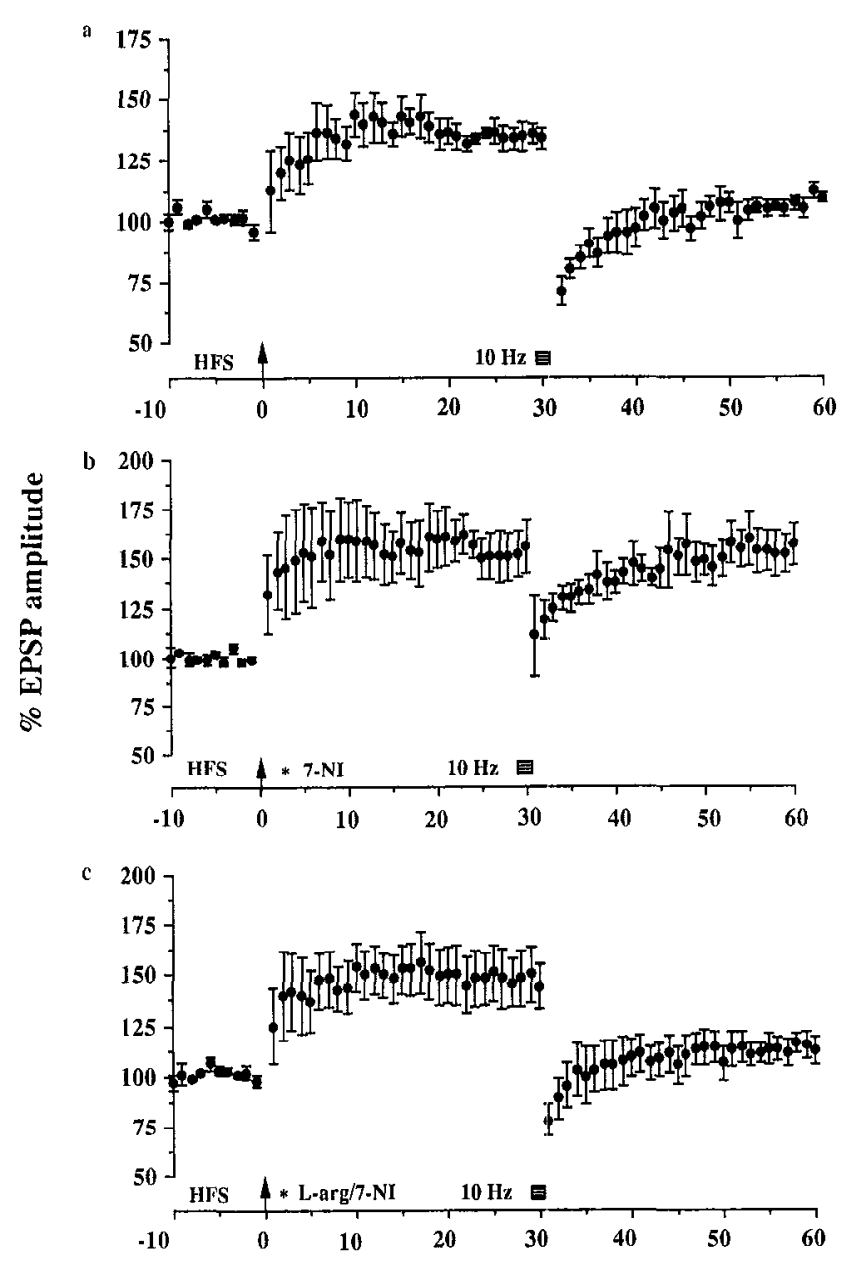

Time (min)

Figure 3. The effect of 7-NI on induction of DP of the field EPSP. $a$, In control experiments, LTP was induced by high-frequency stimulation (LTP $135 \pm 5 \%, n=5$ ) and low-frequency stimulation (900 stimuli at 10 $\mathrm{Hz})$ induced DP to $108 \pm 3 \%(n=5) . b, 7-\mathrm{NI}(30 \mathrm{mg} / \mathrm{kg}$, i.p. $)$ applied 1 min after LTP induction inhibited induction of DP of the EPSP. In these experiments, high-frequency stimulation induced LTP of $152 \pm 12 \%(n=$ 6). Low-frequency stimulation applied $30 \mathrm{~min}$ after the induction of LTP induced only a short-term depression, and induced no DP with the EPSP fully recovering to a value not significantly different from the previous potentiated level $(154 \pm 11 \%)$, c, L-Arginine $(225 \mathrm{mg} / \mathrm{kg}$, i.p.) prevented the 7-NI block of DP. LTP of $147 \pm 13 \%(n=7)$ was induced by high-frequency stimulation. L-Arginine injected $1 \mathrm{~min}$ before injection of 7-NI resulted in a large DP to $113 \pm 6$, being induced by low-frequency stimulation, a DP of $72 \%$, which is a value significantly different from that of the animals injected with 7-NI alone. All drug administrations are indicated by asterisks. Low-frequency stimulation is indicated by the hatched box; high-frequency stimulation (HFS) is indicated by arrows.

a single, high-frequency stimulation compared with a pretetanus baseline of $101 \pm 2 \%(n=4)$.

CPP ( $7 \mathrm{mg} / \mathrm{kg}$, i.p.) also blocked the induction of DP (Fig. $4 b$ ). In these experiments, LTP was induced measuring $147 \pm$ $6 \%$ at $30 \mathrm{~min}$ after high-frequency stimulation. CPP was injected at 2-3 min after LTP induction, and $10 \mathrm{~Hz}$ stimulation (900 pulses) was given at $30 \mathrm{~min}$ after the induction of LTP. LTP at 15-20 min after the $10 \mathrm{~Hz}$ stimulation measured $144 \pm$ $7 \%(n=5)$, a value that was not significantly different from that before $10 \mathrm{~Hz}$ stimulation, i.e., no DP had been induced in the presence of CPP. 


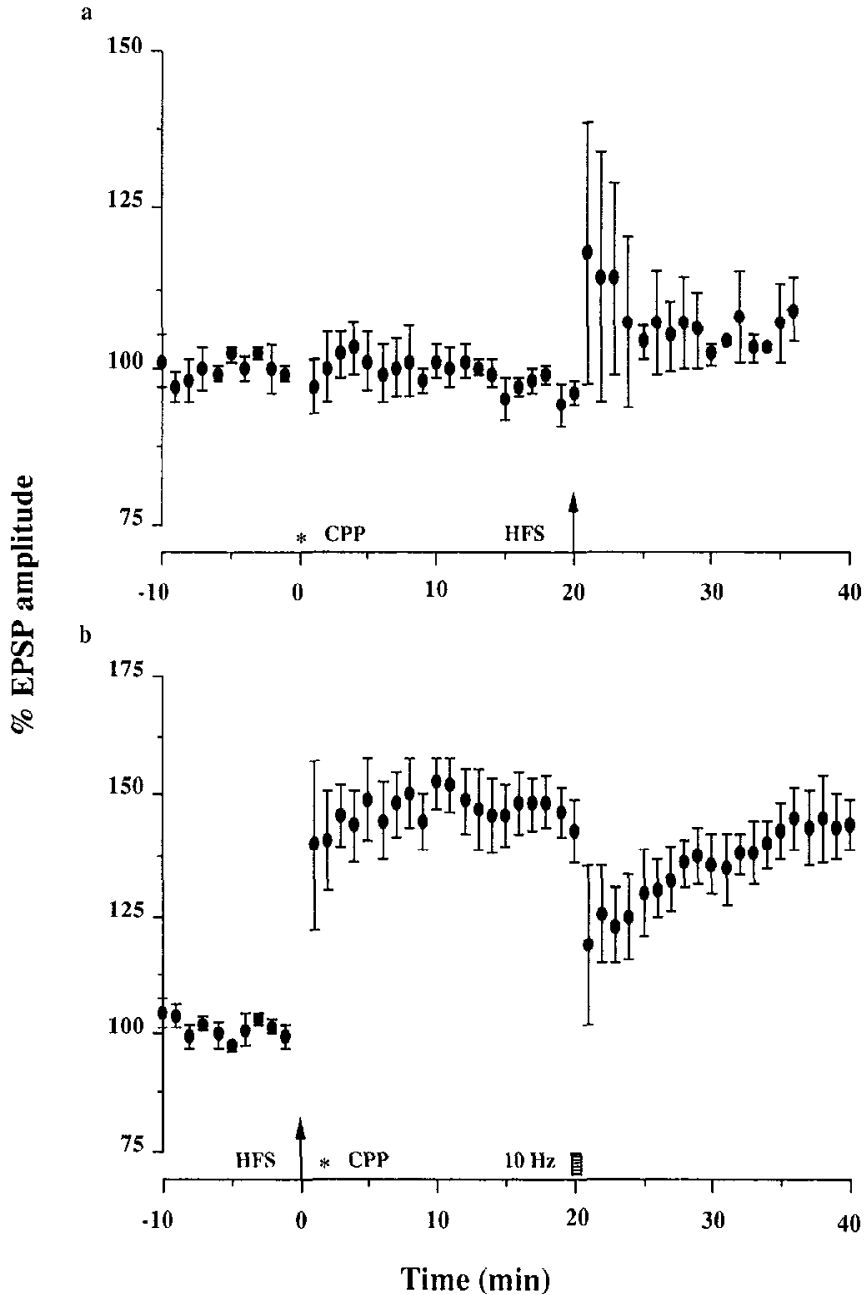

Figure 4. The NMDA antagonist CPP blocked the induction of LTP and DP. $a$, CPP $(7 \mathrm{mg} / \mathrm{kg}$, i.p.) inhibited the production of LTP, the EPSP measuring only $106 \pm 4 \%$ at $20 \mathrm{~min}$ after high-frequency stimulation in rats injected with CPP $(n=4) . b$, CPP $(7 \mathrm{mg} / \mathrm{kg}$, i.p.) inhibited the induction of DP [LTP $144 \pm 6 \%(n=5)$ before low-frequency stimulation vs $144 \pm 7 \%$ at $20 \mathrm{~min}$ after low-frequency stimulation]. CPP was applied at the point indicated by an asterisk.

\section{DISCUSSION}

The results of the present study show clearly that 7-NI prevents the induction of I.TP and that L-arginine, the substrate amino acid used by NOS for NO production, prevented this effect. Thus, these studies support the theory that stimulation of NO production is necessary for the induction of LTP in vivo in the CA1 region of the hippocampus. The action of 7-NI was particularly effective in the present studies, with LTP induction being completely abolished by 7-NI. This is the first demonstration in vivo that an NOS inhibitor blocks the induction of LTP of the EPSP. Previous studies by Saito's group (Iga et al., 1993; Mitzuni et al., 1993) have reported that the NOS inhibitors L-NAME and LNMMA blocked LTP induction of the population spike by $\sim 60 \%$, but in such studies the effects of NO could have been exerted via a change in spike threshold rather than a change in excitatory synaptic transmission. Although many previous in vitro studies have found a residual STP lasting $15-45 \mathrm{~min}$ in the presence of NOS inhibitors (Schuman and Madison, 1991; Haley et al., 1992), others have shown a complete block of STP and LTP (Bohme et al., 1991; Bon et al., 1992). The present conclusions contrast with those of Bannerman et al. (1994a,b), who failed to show that L-NAME inhibited the induction of LTP of the EPSP in the dentate gyrus. The effect of L-NAME in the study of Bannerman et al. (1994b) could not be assessed easily because it produced a large decrease in baseline synaptic transmission. L-NAME is unsatisfactory for systemic use, because it produces a significant increase in arterial blood pressure that results in a decreased blood flow to many brain regions, including the hippocampus (Bannerman et al., 1994b), and probably leads to a reduction in synaptic transmission. In comparison, 7-NI appears to be selective in its antagonism of nNOS when given systemically, having no effect on arterial blood pressure in the dose range used (Moore et al., 1993a,b) and no significant effect on baseline transmission in the present experiments. Thus, the lack of change in blood pressure, which has been confirmed by Connop et al. (1994) using a dose of $80 \mathrm{mg} / \mathrm{kg}$, i.p., may have been responsible for the difference with the Bannerman et al. (1994b) study. Alternatively, because intracerebroventricular L-NAME did not decrease either baseline EPSPs or LTP (Bannerman et al., 1994a), there may be a difference in the role of NO between the dentate gyrus and CA1. As summarized in the introductory remarks, most previous in vitro studies that found a significant effect of NOS antagonists on LTP in the hippocampus were carried out in CA1. The observation that L-arginine prevented the inhibitory action of 7-NI on LTP induction is in agreement with in vitro studies in which the blocking action of the NOS inhibitors L-NAME and L-NMMA on LTP induction was opposed by L-arginine (Schuman and Madison, 1991; Haley et al., 1992; Nowicky and Bindman, 1993). Furthermore, these findings provide confirmation that the site of action of 7-NI, indeed, was NOS. It is interesting to note that the effect of 7-NI appeared to be rapidly reversible, robust LTP being generated $4 \mathrm{hr}$ after the injection. This indicates that a critical level of NO can be generated even at a time when there still should be considerable enzyme inhibition ( $45 \%)$ (Mackenzie el al., 1994).

7-NI has been shown to be specific for neuronal NOS after systemic injection (Babbedge et al., 1993; Moore et al., 1993a,b) and, therefore, the results of the present paper demonstrate that neuronal NOS generates NO during the induction of LTP. Such a conclusion differs from that of the study of O'Dell et al. (1994), in which it was shown that LTP induced by either weak or strong high-frequency stimulation, and the inhibition of such LTP by nonselective NOS antagonism, was very similar in both wild-type and mutant mice lacking nNOS. These authors suggested that endothelial NOS rather than neuronal NOS generates NO during the induction of LTP. However, because both neuronal and endothelial NOS isoforms have been found to be expressed in CA1 pyramidal cells (Chiang et al., 1994; O'Dell et al., 1994), perhaps neuronal and endothelial isoforms generate NO during LTP induction. Several studies have shown that NOS can be induced in neurons in a use-dependent manner (Kato el al., 1994; LernerNatoli et al., 1994; Al-Ghoul et al., 1995). The presence of LTP in the nNOS knock-out mice, therefore, may be attributable to compensatory induction of the endothelial form during development. Other adaptive changes in LTP induction mechanisms and a possible species difference may provide an explanation for this apparent discrepancy.

7-NI also was found in the present studies to inhibit the induction of DP. The action of $7-\mathrm{NI}$ was very effective, resulting in a complete block of DP, and the block was prevented by L-arginine. This is the first demonstration that the induction of DP is blocked in vivo by an NOS inhibitor. The NOS inhibitors L-NMMA and L-NOARG were found previously to inhibit long-term depression 
(LTD) and DP in vitro in one study (Izumi and Zorumski, 1993), but L-NOARG was ineffective in blocking LTD in two other studies (Lum-Ragan and Gribkoff, 1993; Cummings et al., 1994).

As detailed above, many studies either have been unable to demonstrate a blocking action of NOS on the induction of changes in synaptic strength in CA1 in vitro or have found that the blocking action occurred only under specific conditions of temperature, age of animal, or stimulation protocol. Such variation in the action of NOS inhibitors may be attributable to at least three factors. First, NO appears to have directly opposing actions on LTP induction, one that facilitates LTP induction and one that inhibits LTP induction. Evidence for the latter has come from studies showing that in CA1 in vitro, NOS inhibitors facilitated LTP induced by weak stimulation (Kato and Zorumski, 1993), and NOS inhibitors reversed the "untimely" NMDA receptoractivated induced block of LTP (Izumi et al., 1992). Second, the inconsistency of studies on NOS inhibitors and synaptic plasticity may be attributable to NO inducing LTD/DP, which could occlude LTP. Third, because NO is a relatively unstable gas, the in vitro conditions required to show that it has a role in synaptic plasticity may be difficult to reproduce.

The finding that very similar results were obtained with the NMDA receptor antagonists CPP and 7-NI on LTP/DP is consistent with the view that NOS activation by the high-frequency/lowfrequency stimulation is NMDA receptor-mediated. To our knowledge, this is the first report of NMDA receptor dependence of DP in vivo. The discrepancy with regard to the presence of a transient depression after high-frequency stimulation in the presence of 7-NI but not when CPP was used may be dose-related. NMDA receptors allow calcium entry, which is an essential factor for nNOS activity. NMDA receptors are believed to be essential for certain hippocampal-dependent forms of learning. In a related article, we report that 7-NI impaired rats in spatial tasks (our unpublished observations). The block of LTP and DP by NMDA receptor antagonists and an NOS inhibitor in the present article suggests that a role for LTP and DP in lcarning and memory should be considered.

\section{REFERENCES}

Al-Ghoul WM, Meeker RB, Greenwood RS (1995) Kindling induces a long-lasting increase in brain nitric oxide synthase activity. NeuroReport 6:457-460.

Babbedge RC, Blandward PA, Hart SL, Moore PK (1993) Inhibition of rat cerebellar nitric oxide synthase by 7 -nitro-indazole and related substituted indazoles. Br J Pharmacol 110:225-228.

Bannerman DM, Butcher SP, Morris RGM (1994a) Intracerebroventricular injection of a nitric oxide synthase inhibitor does not affect long-term slope potentiation in vivo. Neuropharmacology 33:1387-1397.

Bannerman DM, Chapman PF, Kelly PAT, Butcher SP, Morris RGM (1994b) Inhibition of nitric oxide synthase does not prevent the induction of long-term potentiation in vivo. J Neurosci 14:7415-7425.

Barrionuevo G, Schottler F, Lynch G (1980) The effects of repetitive low frequency stimulation on control and potentiated responses in the hippocampus. Life Sci 27:2385-2389.

Bliss TVP, Collingridge GL (1993) A synaptic model of memory: longterm potentiation in the hippocampus. Nature 361:31-39.

Bliss TVP, Lomo T (1973) Long-lasting potentiation of synaptic transmission in the dentate area of anaesthetized rabbit following stimulation of the perforant pathway. J Physiol (Lond) 232:331-356.

Bohme GA, Bon C, Stutzmann J-M, Doble A, Blanchard J-C (1991) Possible involvement of nitric oxide in long-term potentiation. Eur J Pharmacol 199:379-381.

Bon C, Bohme A, Doble A, Stutzmann J-M, Blanchard J-C (1992) A role for nitric oxide in long-term potentiation. Eur J Neurosci 4:420-424.

Boulton C, Irving AJ, Southam E, Potier B, Garthwaite J, Collingridge GL (1994) The nitric oxide-cyclic GMP pathway and synaptic depression in rat hippocampal slices. Eur J Pharmacol 6:1528-1535.
Bredt DS, Snyder SH (1989) Nitric oxide mediates glutamate-linked enhancement of cGMP levels in the ccrebellum. Proc Natl Acad Sci USA 86:9030-9033.

Buxton LO, Cheek DJ, Eckman D, Westfall DP, Saunders KM, Keef KD (1993) $\mathrm{N}^{\mathrm{G}}$-nitro-L-arginine methyl ester and other alkyl esters of arginine are muscarinic receptor antagonists. Circ Res 72:387-395.

Chetkovitch DM, Klann E, Sweatt, JD (1993) Nitric oxide synthaseindependent long-term potentiation in area CA1 of hippocampus. NeuroReport 4:919-922.

Chiang LW, Schweizer FE, Tsien RW, SchuIman H (1994) Nitric oxide synthase expression in single hippocampal neurons. Mol Brain Res $27: 183-188$

Collingridge GL, Kehl SJ, McLennan $\mathbf{H}$ (1983) The antagonism of amino acid-induced excitations of rat hippocampal CA1 neurons in vitro. J Physiol (Lond) 334:19-31.

Connop BP, Rolfe NG, Boegman RJ, Jhamandas K, Beninger RJ (1994) Potentiation of NMDA-mediated toxicity by a low dose of 7-nitroindazole. Neuropharmacology 33:1439-1445.

Cummings JA, Nicola SM, Malenka RC (1994) Induction in the rat hippocampus of long-term potentiation (LTP) and long-term depression (LTD) in the presence of a nitric oxide synthase inhibitor. Neurosci Lett 176:110-114.

Dolphin A, Errington ML, Bliss TVP (1982) Long-term potentiation of the perforant path in vivo is associated with increased glutamate release. Nature 297:496-498.

Gally JA, Read MP, Reeke GN, Edelman GM (1990) The NO hypothesis: possible effects of a short-lived, rapidly diffusible signal in the development and function of the nervous system. Proc Natl Acad Sci USA 87:3547-3551.

Garthwaite J, Charles SL, Chess-Williams R (1988) Endothelial-derived relaxing factor release on activation of NMDA receptors suggests a rolc as intercellular messcnger in the brain. Nature 336:385-387.

Gribkoff VK, Lum-Ragan J (1992) Evidence for nitric oxide synthase inhibitor-sensitive and insensitive hippocampal synaptic potentiation J Neurophysiol 68:639-642.

Haley JE, Malen PL, Chapman PF (1993) Nitric oxide synthase inhibitors block long-term potentiation induced by weak but not strong tetanic stimulation at physiological brain temperatures in rat hippocampal slices. Neurosci Lett 160:85-88.

Haley JE, Wilcox GL, Chapman PF (1992) The role of nitric oxide in hippocampal long-term potentiation. Neuron 8:211-216.

Iga Y, Yoshioka M, Togashi H, Saito H (1993) Inhibitory action of $\mathrm{N}^{\mathrm{r}}$-nitro-L-arginine methyl ester on in vivo long-term potentiation. Eur J Pharmacol 238:395-398.

Izumi Y, Clifford DB, Zorumski CF (1992) Inhibition of long-term potentiation by NMDA-mediated nitric oxide release. Science 257:1273-1276.

Izumi Y, Zorumski CF (1993) Nitric oxide and long-term synaptic depression in the rat hippocampus. NeuroReport 4:1131-1134.

Kato K, Zorumski CF (1993) Nitric oxide inhibitors facilitate the induction of hippocampal long-term potentiation by modulating NMDA responses. J Neurophysiol 70:1260-1263.

Kato H, Kogure K, Liu Y, Araki T, Itoyama Y (1994) Induction of NADPH-diaphorase activity in the hippocampus in a rat model of cerebral ischemia and ischemic tolerance. Brain Res 652:71-75.

Lerner-Natoli M, De Bock F, Bockaert J, Rondouin G (1994) NADOPH diaphorase-positive cells in the brain after status epilepticus. NeuroReport 5:2633-2637.

Linden DJ (1994) Long-term synaptic depression in the mammalian brain. Neuron 12:457-472.

Lot TY, Stark G, Wilson VG (1993) Endothelium-dependent contractions to $\mathrm{N}^{G}$-nitro-L-arginine methyl ester in the porcine isolated splenic artery are sensitive to cyclooxygenase and lipoxygenase inhibitors. Naunyn Schmiedebergs Arch Pharmacol 347:115-118.

Lum-Ragan JT, Gribkoff VK (1993) The sensitivity of hippocampal longterm potentiation to nitric oxide synthase inhibitors is dependent upon the pattern of conditioning stimulation. Neuroscience 57:973-983.

Mackenzie GM, Rose S, Bland-Ward PA, Moore PK, Jenner P, Marsden CD (1994) Time course of inhibition of brain nitric oxide synthase by 7-nitro indazole. NeuroReport 5:1993-1996.

Mitzuni A, Saito H, Abe K (1993) Involvement of nitric oxide in longterm potentiation in the dentate gyrus in vivo. Brain Res 605:309-311.

Moore PK, Babbedge RC, Wallace P, Garren ZA, Ilart SL (1993a) 7-Nitro indazole, an inhibitor of nitric oxide synthase, exhibits antino- 
ciceptive activity in the mouse without increasing blood pressure. $\mathrm{Br} \mathrm{J}$ Pharmacol 108:296-297.

Moore PK, Wallace P, Gaffen Z, Hart SL, Babbedge RC (1993) Characterization of the novel nitric oxide synthase inhibitor 7-nitro indazole and related indazoles: antinociceptive and cardiovascular effects. $\mathrm{Br} \mathrm{J}$ Pharmacol 110:219-224.

Nicolarakis PJ, Lin YQ, Bennett MR (1994) Effect of nitric oxide synthase inhibition on long-term potentiation at associational-commissural and mossy fibre synapse on CA3 pyramidal neurones. Br J Pharmacol 111:521-524

Nowicky AV, Bindman LJ (1993) The nitric oxide synthase inhibitor, $\mathrm{N}$-monomethyl-L-arginine blocks induction of a long-term potentiationlike phenomenon in rat medial frontal cortical neurons in vitro. J Neurophysiol 70:1255-1259.

O'Dell TJ, Hawkins RD, Kandel ER, Arancio O (1991) Tests of the roles of two diffusible substances in long-term potentiation: evidence for nitric oxide as a possible retrograde messenger. Proc Natl Acad Sci USA $88: 11285-11289$.

O'Dell TJ, Huang PL, Dawson TM, Dinerman JL, Snyder SH, Kandel ER, Fishman MC (1994) Endothelial NOS and the blockade of LTP by NOS inhibitors in mice lacking neuronal NOS. Science 265:542-546.

Schuman EM, Madison DV (1991) A requirement for the intercellular messenger nitric oxide in long-term potentiation. Science 254:1503-1506.

Williams JH, Li Y-G, Nayak A, Errington ML, Murphy KPSJ, Bliss TVP (1993) The suppression of long-term potentiation in the rat hippocampus by inhibitors of nitric oxide synthase is temperature and age dependent. Neuron 11:877-884.

Zhuo M, Small SA, Kandel ER, Hawkins RD (1993) Nitric oxide and carbon monoxide produce activity-dependent long-term synaptic enhancement in hippocampus. Science 260:1946-1950. 